\title{
Development and Validation of Selective High-Performance Liquid Chromatographic Method Using Photodiode Array Detection for Estimation of Aconitine in Polyherbal Ayurvedic Taila Preparations
}

\author{
Nitin Dubey, ${ }^{1}$ Nidhi Dubey, ${ }^{2}$ and Rajendra Mehta $^{3}$ \\ ${ }^{1}$ College of Pharmacy, IPS Academy, Indore, India \\ ${ }^{2}$ School of Pharmacy, Devi Ahilya Vishwavidyalaya, Indore, India \\ ${ }^{3}$ A. R. College of Pharmacy, Vallabh Vidyanagar, India \\ Correspondence should be addressed to Nidhi Dubey, nidhidubeympharm@yahoo.com
}

Received 9 December 2011; Revised 29 January 2012; Accepted 29 January 2012

Academic Editor: Sibel A. Ozkan

Copyright (C) 2012 Nitin Dubey et al. This is an open access article distributed under the Creative Commons Attribution License, which permits unrestricted use, distribution, and reproduction in any medium, provided the original work is properly cited.

A simple, sensitive, and selective high-performance liquid chromatographic (HPLC) method has been developed and validated for the analysis of aconitine in marketed ayurvedic taila (oil) formulations containing roots of Aconitum chasmanthum. Chromatography of methanolic extracts of these formulations was performed on $\mathrm{C}_{18}(5 \mu \mathrm{m} \times 25 \mathrm{~cm} \times 4.6 \mathrm{~mm}$ i.d.) column using isocratic mobile phase consisting of $(65: 35 \% \mathrm{v} / \mathrm{v})$ acetonitrile and buffer solution (aqueous $0.01 \mathrm{M}$ ammonium bicarbonate buffer, adjusted to $\mathrm{pH} 9.6$ using $30 \%$ ammonia solution) at a flow rate of $1 \mathrm{~mL} / \mathrm{min}$ and SPD-10 A The analytical reference, aconitine, was quantified at $238 \mathrm{~nm}$. The retention time of aconitine was about $42.54 \mathrm{~min}$. The linear regression analysis data for the calibration plot showed a good linear relationship with correlation coefficient of 0.9989 in the concentration range of 15 to $90 \mu \mathrm{g} / \mathrm{mL}$ for aconitine with respect to peak area. The limit of detection and limit of quantitation values were found to be $0.03 \mu \mathrm{g} / \mathrm{mL}$ and $0.1 \mu \mathrm{g} / \mathrm{mL}$ respectively. Repeatability of the method was found to be $0.551-1.689$ RSD. Recovery values from 97.75 to $99.91 \%$ indicate excellent accuracy of the method. The developed HPLC method is accurate and precise and it can be successfully applied for the determination of aconitine in marketed ayurvedic oil formulations containing Aconitum chasmanthum.

\section{Introduction}

Aconitum chasmanthum (Family, Ranunculaceae) is a most valuable medicinal plant, widely used in the traditional and folk medicines of a number of countries of south east Asia. The chief chemical constituents of Aconitum chasmanthum root are aconitine, mesaconitine, and hypaconitine, and their respective hydrolyzed analogs are called monoester alkaloids, that is, benzoylaconine, benzoylmesaconine, and benzoylhypaconine [1-3]. Aconitine being the major diterpenoid responsible for the biopotency of Aconitum chasmanthum is recognized as the reference compound [3, 4]. Many polyherbal oil formulations in Indian and Chinese traditional systems of medicine used for control of skin diseases contain aconitum root as major active ingredient $[5,6]$. Polyherbal oil formulations are made with the main objective of incorporating the fat-soluble fraction of the component of herbal drugs to a suitable oil base. Standardization of these formulations in terms of composition is important to ensure quality and safety. Aconitine can be used as analytical reference in the quality control of polyherbal oil formulations containing Aconitum chasmanthum [7-10].

There are reports on the application of various analytical methods for isolation and quantitation of aconitine present in Aconitum chasmanthum, biological fluids and other botanical sources [10-14]. Its estimation in polyherbal traditional medicines especially oil formulation is challenging. But no reported method deals with estimation of aconitine in complex matrix of ayurvedic taila formulations. High-performance liquid chromatography has emerged as an efficient 
tool for the phytochemical evaluation of herbal drugs because of its simplicity, sensitivity, accuracy, suitability for high-throughput screening, and so forth [15-21]. Hence it was thought worthwhile to develop a simple chromatographic method for determination of aconitine in ayurvedic taila formulations. The method was validated and found to be sensitive and reproducible $[22,23]$.

\section{Material and Methods}

2.1. Reference Compound and Reagents. Reference aconitine ( $95 \% \mathrm{w} / \mathrm{v}$ purity) was purchased from Sigma-Aldrich (Germany). All the chemicals used in analysis were of AR grade except those used for HPLC analyses which were of HPLC grade. All A.R. grade chemicals were procured from S.D. fine chemicals, Mumbai and all HPLC grade solvents were procured from Merck, Mumbai.

2.2. Polyherbal Oil Formulations. Commercial marketed ayurvedic polyherbal oil formulations "Varnaraksasa taila" and "Vipritmalla taila" which contain Aconitum chasmanthum as one of the components were selected for studies. Vranaraksasa taila is a polyherbomineral oil containing mercury, sulphur, cinnabar $(\mathrm{HgS})$, realgar $\left(\mathrm{As}_{4} \mathrm{~S}_{4}\right)$, fine copper powder, orpiment $\left(\mathrm{As}_{2} \mathrm{~S}_{3}\right)$, Allium sativum bulb (family, Alliaceae), and Aconitum chasmanthum root (family, Ranunculaceae) digested in mustard seed oil (Brassica nigra. Family, Brassicaceae) as per classical Ayurvedic text [5, 6]. Vipritmalla taila contains cinnabar (HgO), Saussurea lappa root (family, Asteraceae), Aconitum chasmanthum root (family, Ranunculaceae), Ferula asafetida resin (family, Apiaceae), Allium sativum bulb (family, Alliaceae), Plumbago zylenicum root (family, Plumbaginaceae), Valeriana wallichii root (family, Valerianaceae), and Gloriosa superba root (family, Liliaceae) digested in mustard seed oil as per classical Ayurvedic text $[5,6]$.

Samples of the same formulations in triplicate, manufactured by three different reputed ayurvedic drug manufacturers were collected from retail pharmacies in Indore, Madhya Pradesh, India.

2.3. Preparation of Standard Solutions. The stock solution of $1 \mathrm{mg} / \mathrm{mL}$ in methanol was prepared after keeping the purity of reference aconitine into consideration. Solution was filtered through Whatman filter paper (no. 1). Aliquots of stock solution were diluted to $5 \mathrm{~mL}$ using methanol to obtain working standards in concentration range from 15 to $90 \mu \mathrm{g} / \mathrm{mL}$.

2.4. Chromatographic Conditions. The mobile phase consisted of acetonitrile: aqueous $0.01 \mathrm{M}$ ammonium bicarbonate buffer, adjusted to $\mathrm{pH} 9.6$ using ammonia solution $(65: 35 \% \mathrm{v} / \mathrm{v})$ at a flow rate of $1 \mathrm{~mL} / \mathrm{min}$. Before use, the mobile phase was degassed by an ultrasonic bath and filtered using $0.4 \mu \mathrm{m}$ membrane filter. Separation was performed at room temperature on HPLC system having a pump (Shimadzu LC $10 \mathrm{AT}_{\mathrm{VP}}$ ) with $20 \mu \mathrm{L}$ Rheodyne injector, Phenomenex Luna $\mathrm{C}_{18}(5 \mu \mathrm{m} \times 25 \mathrm{~cm} \times 4.6 \mathrm{~mm}$ i.d $)$ column, and SPD-10 AVP photodiode array (PDA) UV-Visible detector set at $238 \mathrm{~nm}$ and equipped with CLASS-VP software (Shimadzu. Kyoto, Japan).

2.5. HPLC Analysis of Ayurvedic Taila Preparations. Oil formulations $(10 \mathrm{gm})$ were homogenated using homogenizer (Scientific instruments ltd, Indore) using methanol $(50 \mathrm{~mL}$ ) in proportion of $1: 5, \mathrm{w} / \mathrm{v}$ at $50^{\circ} \mathrm{C}$ for $20 \mathrm{~min}$. The mixture was centrifuged at $2000 \mathrm{rpm}$ for $20 \mathrm{~min}$ at $4^{\circ} \mathrm{C}$ and the supernatant was collected. The residue was resuspended in methanol and the extraction was repeated five more times similarly. The supernatants were pooled and concentrated under vacuum at room temperature and made up to a volume of $20 \mathrm{~mL}$ using methanol. The extracts were filtered through $0.45 \mu \mathrm{m}$ filter and HPLC was performed under the conditions optimized for the reference compound. The amount of aconitine was quantified using calibration curves plotted with the reference compound.

\subsection{Validation of Method}

(a) Calibration Graph (Linearity of the HPLC Method). The calibration curve was obtained at 6 concentration levels of aconitine standard solutions $(15-90 \mu \mathrm{g} / \mathrm{mL})$. The solutions $(20 \mu \mathrm{L})$ were injected into the HPLC system $(n=6)$ with the chromatographic conditions previously given. The linearity was evaluated by the least-squares regression method.

(b) Limits of Detection and Quantification. For determination of the limit of detection (LOD) and the limit of quantification (LOQ) different dilutions of the standard solution of aconitine were analyzed using mobile phase as the blank. The LOD and LOQ were determined on the basis of signalto-noise ratio until the average responses were approximately 3 and 10 times the responses of the blank, respectively.

(c) Accuracy (Recovery). The accuracy of the methods was determined by calculating recovery of aconitine by the standard addition method. Known amounts of standard solution of aconitine (at three levels 50\%, 100\%, 150\%) were added to prequantitated sample solutions. The amount of aconitine was estimated by applying values of peak area to the regression equations of the calibration graph. Five replicate samples of each concentration level were prepared.

(d) Method Precision (Repeatability). The precision of the instruments was checked by repeatedly injecting and analyzing $(n=6)$ standard solutions of aconitine $(45 \mu \mathrm{g} / \mathrm{mL})$. The results are reported in terms of relative standard deviation (RSD).

(e) Intermediate Precision (Reproducibility). The intraday and interday precision of the proposed method were determined by analyzing standard solution of aconitine at 3 different concentrations $(15,45$, and $90 \mu \mathrm{g} / \mathrm{mL})$ three times on the same day and on three different days. The results are reported in terms of RSD. 
(f) Solution Stability and Mobile Phase Stability. Solution stability in the assay method was evaluated by leaving test solutions of sample and reference standard in tightly capped volumetric flasks at room temperature in the dark for $24 \mathrm{~h}$. The same sample solutions were assayed every $6 \mathrm{~h}$ interval in the study period. Mobile phase stability was studied by assaying the freshly prepared sample solutions against freshly prepared reference standard solutions at $6 \mathrm{~h}$ intervals up to $24 \mathrm{~h}$. Mobile phase was prepared and kept constant during the study period. The relative standard deviation (RSD) of the assay of aconitine was calculated for the study period during mobile phase and solution stability experiments.

2.7. Statistical Analysis. The statistical analysis was performed using Microsoft Excel 2003.

\section{Result and Discussion}

The literature revealed that methanol is preferred for extraction of aconitine from Aconitum chasmanthum [10-14]. The same was used for extraction of aconitine from oil formulations. It is advantageous as the base oil in all the selected ayurvedic oil formulations was immiscible in this solvent. The immiscibility of oil in solvent will help in reducing number of interfering components in further chromatographic development. Multiple extractions were carried out to ensure complete extraction.

3.1. Development of the HPLC Method. The method development and selection of a suitable mobile phase involved several trials because of the complexity of the chemical composition of the herbals and the affinities of the components towards various solvents. The proportions of the organic and aqueous phases were adjusted to obtain a simple assay method with a reasonable run time and suitable retention time. Further optimization of mobile phase was performed based on resolution, asymmetric factor, and theoretical plates obtained for aconitine. Different mobile phases were tried like methanol: acetonitrile: water $(45: 45: 10)$ which gave broad peak for aconitine. Combination of acetonitrile: methanol (10:90) was tried which gave broad and tailed peak. A mixture of methanol: water $(60: 40)$ was tried, which gave unresolved peak at retention time $48.9 \mathrm{~min}$. Under optimized conditions HPLC with C18 column and UV detector at $238 \mathrm{~nm}$ using mobile phase (acetonitrile: aqueous $0.01 \mathrm{M}$ ammonium bicarbonate buffer, adjusted to $\mathrm{pH} 9.6$ using $30 \%$ ammonia solution $(65: 35 \% \mathrm{v} / \mathrm{v}))$ gave well-resolved symmetric band for aconitine from its oil formulation (Figure 1). The resolution was found to be 1.7. Retention time was found to be around 42 minutes and aconitine appeared on chromatogram at 42.54 minutes. Retention time of aconitine was found to be of 42.54 minutes.

The method consumes less volume of HPLC solvents. When the same drug solution was injected 6 times, the retention time of the drug was found to be the same (Figure 2).

3.2. Validation of Method. The calibration curve was prepared by plotting the peak area against aconitine concentration; it was found linear in the range of $15-90 \mu \mathrm{g} / \mathrm{mL}$. The

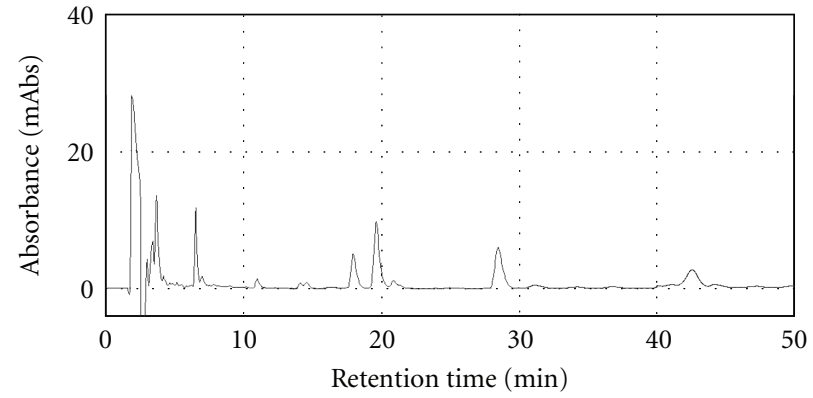

Figure 1: HPLC chromatogram of a $20 \mu \mathrm{L}$ injection of $40 \mu \mathrm{g} / \mathrm{mL}$ reference aconitine at $238 \mathrm{~nm}$.

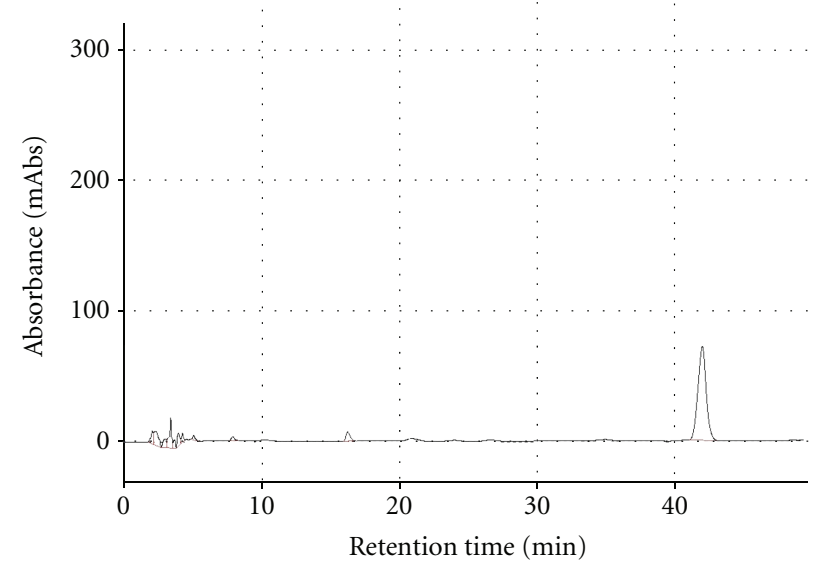

FIGURE 2: HPLC chromatogram of a $20 \mu \mathrm{L}$ injection of the sample of taila preparation at $238 \mathrm{~nm}$.

TABLE 1: Summary of validation parameters and system suitability parameters.

\begin{tabular}{lc}
\hline Parameters & Observations $\pm \%$ RSD $(n=06)$ \\
\hline Retention time $(\mathrm{min})$ & $42.54 \pm 0.33$ \\
Tailing factor & $1.1 \pm 0.1$ \\
Resolution & $1.7 \pm 0.23$ \\
Theoretical plates & $3213 \pm 0.42$ \\
Linearity range $(\mu \mathrm{g} / \mathrm{mL})$ & $15-90$ \\
Correlation coefficient $\left(r^{2}\right)$ & 0.9989 \\
Regression equation & $71.5 x-24.5$ \\
Limit of detection $(\mu \mathrm{g} / \mathrm{mL})$ & 0.03 \\
Limit of quantification $(\mu \mathrm{g} / \mathrm{mL})$ & 0.1 \\
Repeatability $(\% \mathrm{RSD}, n=6)$ & $0.55-1.68$ \\
\hline
\end{tabular}

regression equation was found as $y=71.5 x-24.5\left(r^{2}=\right.$ 0.9989 ), showing excellent linearity (Figure 3 ). The method was validated in terms of precision, repeatability, accuracy, and other validation parameters (Table 1 ). The repeatability of the HPLC method and the intermediate precisions for intraday and interday variations are given in Table 2. The LOD value was found to be $0.03 \mu \mathrm{g} / \mathrm{mL}$, which is the concentration that yields a signal-to-noise $(\mathrm{S} / \mathrm{N})$ ratio of $3 / 1$. The LOQ value under the described conditions was $0.1 \mu \mathrm{g} / \mathrm{mL}$ 


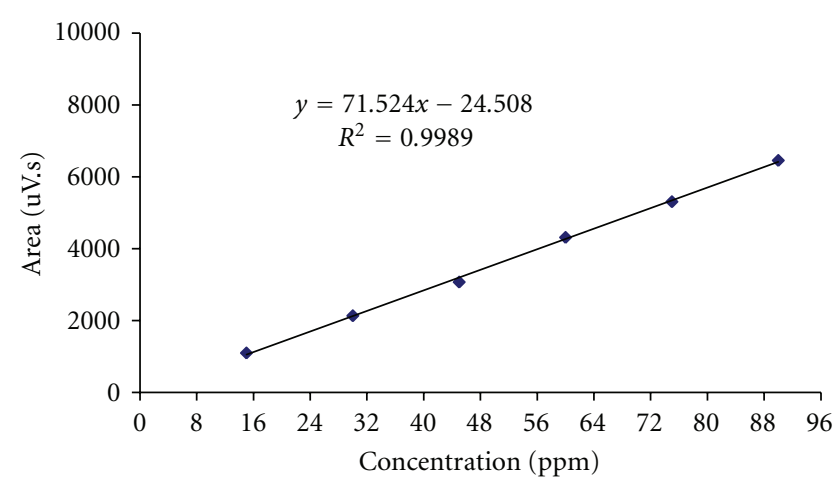

FIGURE 3: Calibration curve of reference aconitine in blank oil sample matrix at $238 \mathrm{~nm}$.

Table 2: Precision studies data for aconitine.

\begin{tabular}{lcccc}
\hline $\begin{array}{l}\text { Concentration } \\
(\mu \mathrm{g} / \mathrm{mL})\end{array}$ & \multicolumn{2}{c}{ Intraday } & \multicolumn{2}{c}{ Interday* } \\
\hline 15 & Peak area $\pm \mathrm{SD}$ & $\% \mathrm{RSD}^{*}$ & Peak area $\pm \mathrm{SD}$ & $\% \mathrm{RSD}^{*}$ \\
45 & $1101.6 \pm 16.7$ & 1.52 & $1112.0 \pm 6.3$ & 0.57 \\
75 & $3059.9 \pm 29.5$ & 0.96 & $3063.0 \pm 29.5$ & 0.96 \\
\hline
\end{tabular}

* Relative standard deviation (\% RSD, $n=3$ ).

with an $\mathrm{S} / \mathrm{N}$ ratio of $10: 1$. This confirmed the sensitivity for quantitation of aconitine in taila preparations. Recovery values from 97.7 to $99.9 \%$ indicate excellent accuracy of the method (Table 3 ). The RSD values of assay of aconitine during solution stability, mobile phase stability and robustness studies (Table 4 ) were within $2.0 \%$. The data obtained in both experiments proves that the sample solutions and mobile phase used during assay were stable up to $24 \mathrm{~h}$.

3.3. HPLC Analysis of Ayurvedic Taila Preparations. Quantitative estimation of aconitine in polyherbal oil formulations given in Table 5 revealed variation in its content in different brands, which indicates the need of standardization of raw material used and uniformity in method of manufacturing to be followed by different ayurvedic manufacturers. The method developed here does not require separation of unsaponifiable matter for quantification as reported for some active ingredients in oil formulation. Oil extract can be directly used for analysis. Avoidance of long and tedious step therefore makes this method more amendable to the highthroughput screening.

\section{Conclusion}

A method for analysis of Aconitum chasmanthum using aconitine as analytical reference in polyherbal oil formulation was developed. Proposed method does not require tedious steps of saponification for separation of fatty acid which are the major interfering component in analysis of oils. Further the method does not require any chemical transformation of active moiety aconitine and it is analyzed as such. The method was found to be simple, precise, specific,
TABLE 3: Accuracy study of the proposed method for aconitine.

\begin{tabular}{|c|c|c|c|}
\hline $\begin{array}{l}\text { Amount detected } \\
\text { in sample }(\mu \mathrm{g} / \mathrm{mL})\end{array}$ & $\begin{array}{c}\text { Amount of } \\
\text { standard drug } \\
\text { added }(\mu \mathrm{g} / \mathrm{mL})\end{array}$ & $\begin{array}{l}\text { Amount of } \\
\text { drug recovered } \\
(\mu \mathrm{g} / \mathrm{mL})^{*}\end{array}$ & $\%$ Recovery* \\
\hline \multicolumn{4}{|l|}{ Varnaraksasa taila } \\
\hline 28.3 & 0 & $27.6 \pm 0.4$ & $97.7 \pm 1.6$ \\
\hline 28.3 & 14 & $41.7 \pm 0.2$ & $98.6 \pm 0.5$ \\
\hline 28.3 & 28 & $56.2 \pm 0.3$ & $99.9 \pm 0.6$ \\
\hline 28.3 & 42 & $69.2 \pm 0.4$ & $98.5 \pm 0.5$ \\
\hline \multicolumn{4}{|l|}{ Vipritmalla taila } \\
\hline 32.2 & 0 & $31.8 \pm 0.2$ & $98.7 \pm 0.6$ \\
\hline 32.2 & 16 & $47.9 \pm 0.4$ & $99.4 \pm 0.2$ \\
\hline 32.2 & 32 & $65.4 \pm 0.3$ & $101.8 \pm 0.5$ \\
\hline 32.2 & 48 & $80.4 \pm 0.5$ & $100.2 \pm 0.7$ \\
\hline \multicolumn{4}{|c|}{${ }^{*}$ Mean value \pm relative standard deviation ( $\%$ RSD, $n=3$ ) } \\
\hline \multicolumn{4}{|c|}{ TABLE 4: Results of robustness studies. } \\
\hline \multicolumn{2}{|c|}{ Parameter } & \multicolumn{2}{|c|}{$\%$ RSD peak area } \\
\hline \multicolumn{2}{|c|}{ Mobile phase composition } & \multicolumn{2}{|c|}{1.22} \\
\hline \multicolumn{2}{|c|}{ Amount of mobile phase } & \multicolumn{2}{|r|}{0.83} \\
\hline \multicolumn{2}{|c|}{ Temperature } & \multicolumn{2}{|r|}{0.92} \\
\hline \multicolumn{2}{|c|}{ Chamber saturation time } & \multicolumn{2}{|r|}{0.71} \\
\hline \multicolumn{2}{|c|}{ Chamber dimensions } & \multicolumn{2}{|r|}{0.43} \\
\hline
\end{tabular}

TABLE 5: Aconitine content found in various taila preparations.

\begin{tabular}{lcc}
\hline Sample & Brand & $\begin{array}{c}\text { Aconitine content in oil } \\
(\mathrm{mg} / 100 \mathrm{gm})\end{array}$ \\
\hline Varnaraksasa taila & 1 & $0.27 \pm 0.003$ \\
& 2 & $0.28 \pm 0.005$ \\
Vipritmalla taila & 3 & $0.26 \pm 0.004$ \\
\hline & 2 & $0.31 \pm 0.05$ \\
& 3 & $0.32 \pm 0.07$ \\
\hline
\end{tabular}

${ }^{*}$ Mean \pm relative standard deviation $(\mathrm{RSD}, n=3)$.

sensitive, and accurate. It can be used for routine quality control of polyherbal oil formulations containing Aconitum chasmanthum.

\section{Acknowledgments}

The authors are thankful to School of Pharmacy, DAVV University, Indore (Madhya Pradesh) and Director, SICART, V. V. Nagar (Gujarat) for providing analytical facilities.

\section{References}

[1] The Ayurvedic Pharmacopoeia of India-part I, Ministry of Health and Family Welfare, Government of India, New Delhi, India, 1st edition, 2000.

[2] H. M. Chang and P. P. H. But, Pharmacology and Applications of Chinese Materia Medica, vol. 1-2, World scientific press, Singapore, Singapore, 1987. 
[3] G.E. Trease and W.C. Evans, Pharmacognosy, Saunders/Elsevier Science, Amsterdam, The Netherlands, 15th edition, 2002.

[4] P.K. Mukherjee, Quality Control of Herbal Drugs, Business Horizons, New Delhi, India, 1st edition, 2002.

[5] The Ayurvedic formulary of India-part III, Ministry of Health and Family Welfare, Government of India, New Delhi,India, 1 st edition, 2000.

[6] R. N. Sharma, Ayurveda-sarsangrha, Shri Baidhyanath Ayurveda Bhavan Ltd., Varnasi, India, 13th edition, 1985.

[7] Anonymous, "Natural health product directorate," 2006, Canada, version 2, http://www.hc-sc.gc.ca/dhp-mps/prodnatur/ legislation/docs/compendium_mono_table_8-eng.php.

[8] EMEA/HMPC/253629/2007, Reflection paper on references used for quantitative and qualitative analysis of herbal medicinal products and traditional herbal medicinal products.

[9] EMEA/HMPC/CHMP/CVMP/214869/2006, Guideline on quality of combination herbal medicinal products / traditional herbal medicinal products.

[10] N. Dubey, N. Dubey, R. Mehta, and A. Saluja, "Selective determination of aconitine in polyherbal oils containing aconitum chasmanthum using HPTLC," Journal of AOAC International, vol. 92, no. 6, pp. 1617-1621, 2009.

[11] H. Hikino, O. Ishikawa, C. Konno, and H. Watanabe, "Determination of aconitine alkaloids by high-performance liquid chromatography," Journal of Chromatography, vol. 211, no. 1, pp. 123-128, 1981.

[12] H. Hikino, M. Murakami, C. Konno, and H. Watanabe, "Determination of aconitine alkaloids in aconitum roots," Planta Medica, vol. 48, no. 2, pp. 67-71, 1983.

[13] Y. Xie, Z.H. Jiang, H. Zhou, H.X. Xu, and L. Liu, "Simultaneous determination of six Aconitum alkaloids in proprietary Chinese medicines by high-performance liquid chromatography," Journal of Chromatography A, vol. 1093, no. 1-2, pp. 195203, 2005.

[14] Z. Wang, J. Wen, J. Xing, and Y. He, "Quantitative determination of diterpenoid alkaloids in four species of Aconitum by HPLC," Journal of Pharmaceutical and Biomedical Analysis, vol. 40, no. 4, pp. 1031-1034, 2006.

[15] E. Frérot and E. Decorzant, "Quantification of total furocoumarins in citrus oils by HPLC coupled with UV, fluorescence, and mass detection," Journal of Agricultural and Food Chemistry, vol. 52, no. 23, pp. 6879-6886, 2004.

[16] Y. J. Hsieh, L. C. Lin, and T. H. Tsai, "Determination and identification of plumbagin from the roots of Plumbago zeylanica L. by liquid chromatography with tandem mass spectrometry," Journal of Chromatography A, vol. 1083, no. 1-2, pp. 141-145, 2005.

[17] Y. Novikova and A. A. Tulaganov, "Using HPLC for the quality control of psoralen and related preparations," Pharmaceutical Chemistry Journal, vol. 38, no. 5, pp. 50-52, 2004.

[18] A. P. Neilson, R. J. Green, K. V. Wood, and M. G. Ferruzzi, "High-throughput analysis of catechins and theaflavins by high performance liquid chromatography with diode array detection," Journal of Chromatography A, vol. 1132, no. 1-2, pp. 132-140, 2006.

[19] X. R. Yang, C. X. Ye, J. K. Xu, and Y. M. Jiang, "Simultaneous analysis of purine alkaloids and catechins in Camellia sinensis, Camellia ptilophylla and Camellia assamica var. kucha by HPLC," Food Chemistry, vol. 100, no. 3, pp. 1132-1136, 2007.

[20] F. Q. Yang, Y. T. Wang, and S. P. Li, "Simultaneous determination of 11 characteristic components in three species of Curcuma rhizomes using pressurized liquid extraction and high-performance liquid chromatography," Journal of Chromatography A, vol. 1134, no. 1-2, pp. 226-231, 2006.
[21] T. Wu, S. W. Annie Bligh, L. Gu et al., "Simultaneous determination of six isoflavonoids in commercial Radix Astragali by HPLC-UV," Fitoterapia, vol. 76, no. 2, pp. 157-165, 2005.

[22] D.M. Bliesner, Validating Chromatographic Methods: A Practical Guide, John Wiley \& Sons, Toronto, Canada, 2006.

[23] ICH, "Validation of analytical procedures: methodology Q2 (R1)," in Proceedings of The International Conference on Harmonisation of Technical Requirements for Registration of Pharmaceuticals for Human Use, IFPMA, November 1996. 


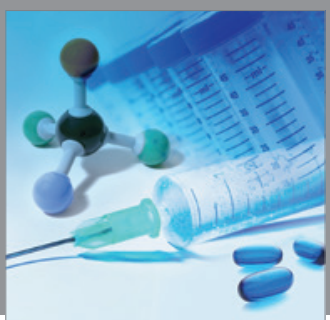

International Journal of

Medicinal Chemistry

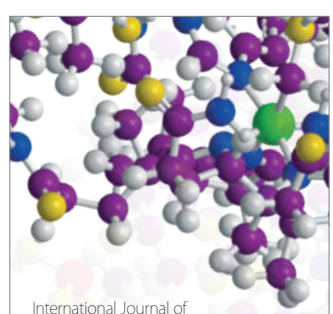

Carbohydrate Chemistry

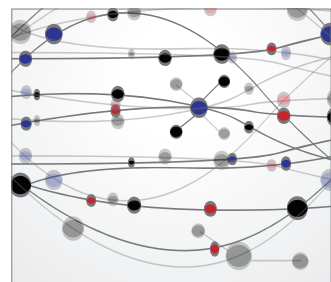

The Scientific World Journal
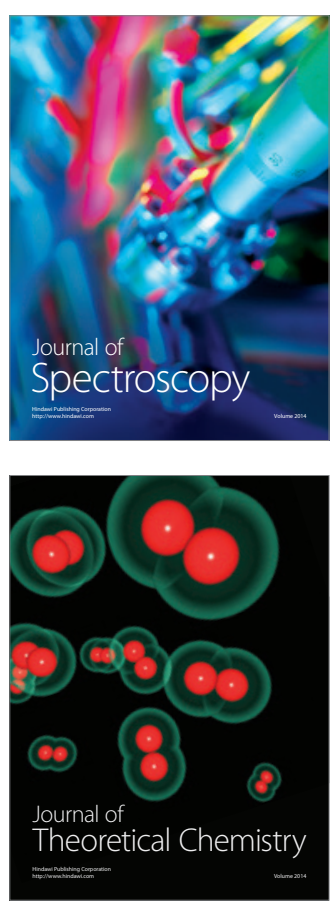
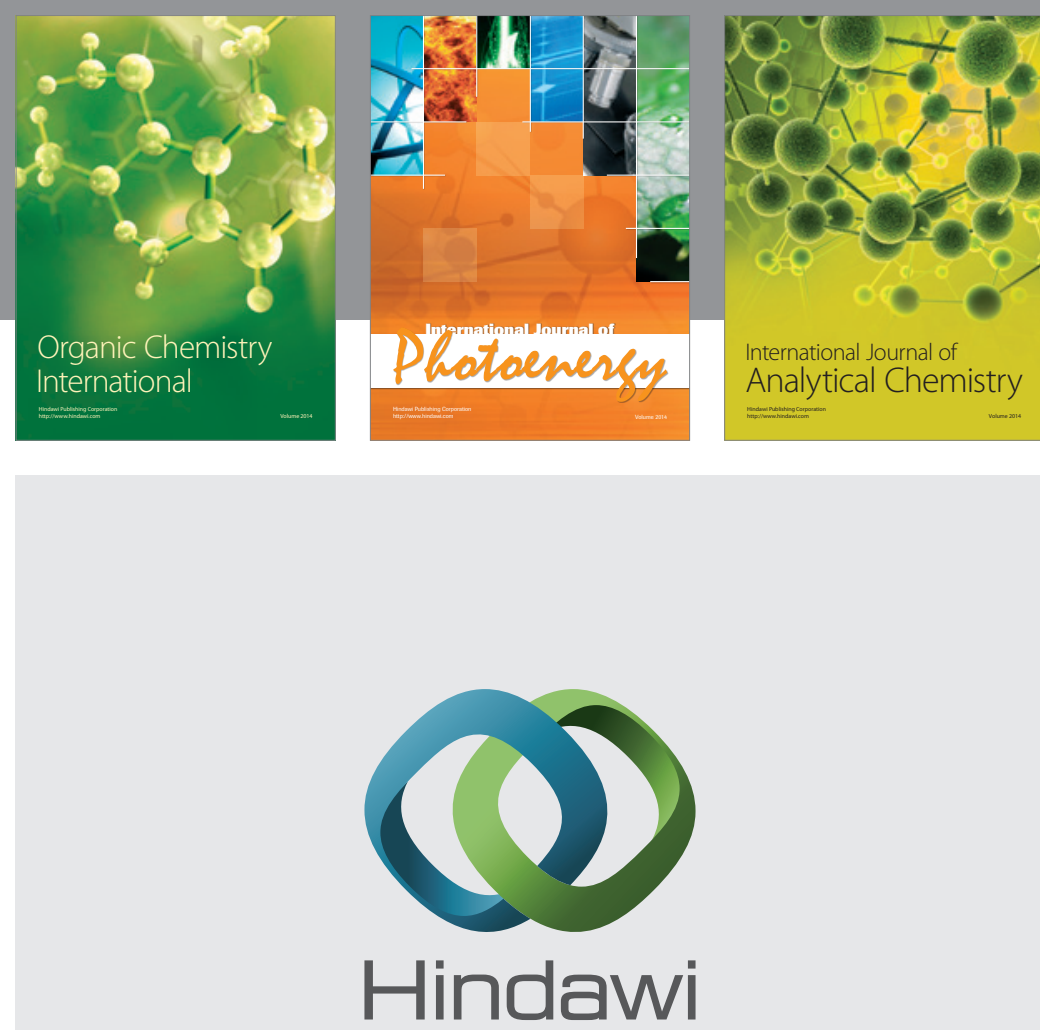

Submit your manuscripts at

http://www.hindawi.com
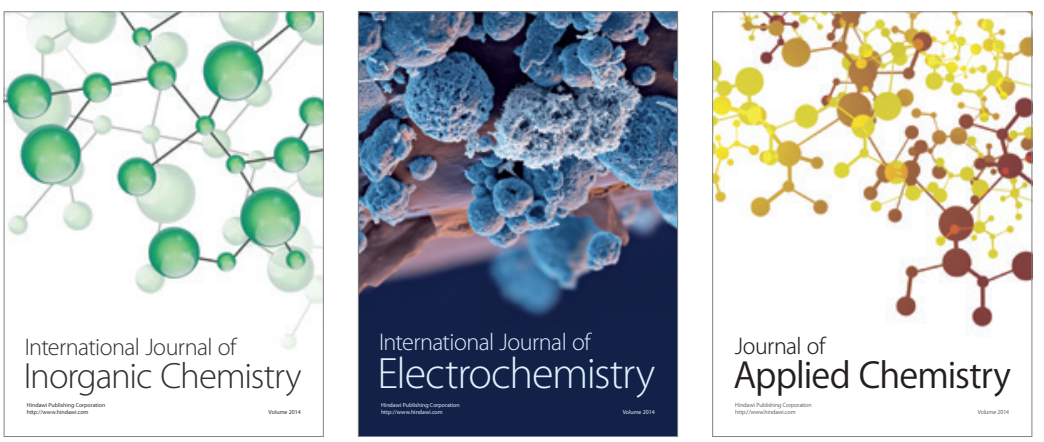

Journal of

Applied Chemistry
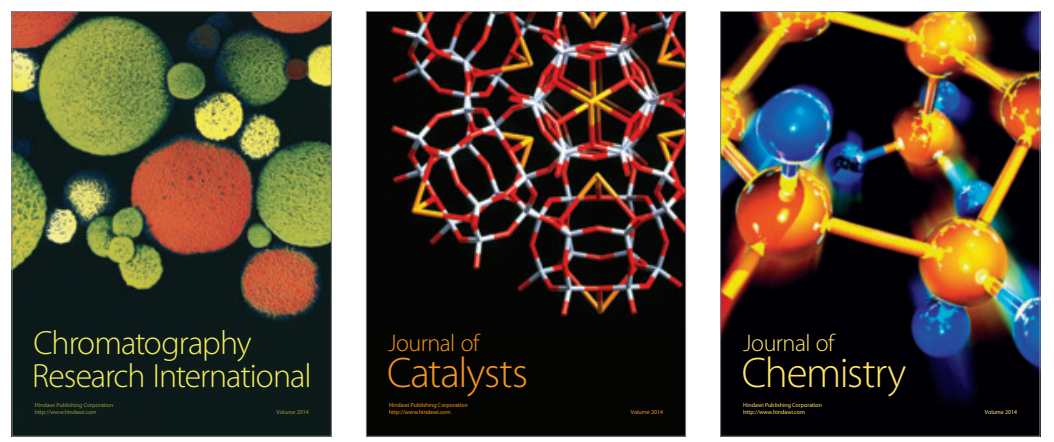
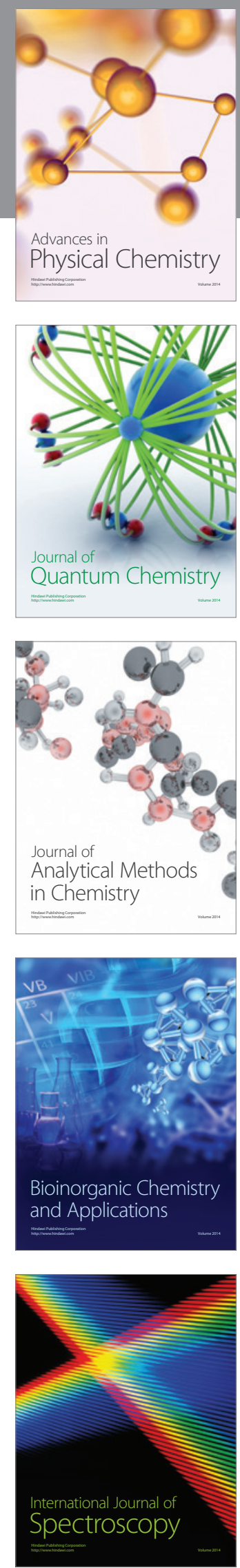